\title{
Evaluation of left ventricular torsion by cardiovascular magnetic resonance
}

\author{
Alistair A Young ${ }^{*}$ and Brett R Cowan
}

\begin{abstract}
Recently there has been considerable interest in LV torsion and its relationship with symptomatic and pre-symptomatic disease processes. Torsion gives useful additional information about myocardial tissue performance in both systolic and diastolic function. CMR assessment of LV torsion is simply and efficiently performed. However, there is currently a wide variation in the reporting of torsional motion and the procedures used for its calculation. For example, torsion has been presented as twist (degrees), twist per length (degrees $/ \mathrm{mm}$ ), shear angle (degrees), and shear strain (dimensionless). This paper reviews current clinical applications and shows how torsion can give insights into LV mechanics and the influence of LV geometry and myocyte fiber architecture on cardiac function. Finally, it provides recommendations for CMR measurement protocols, attempts to stimulate standardization of torsion calculation, and suggests areas of useful future research.
\end{abstract}

\section{Review \\ Background}

Left ventricular torsion has long been recognized as a characteristic of normal mammalian cardiac function, described by William Harvey and many others [1,2]. Relative to end-diastole (ED) the apex of the left ventricle rotates anticlockwise about its central axis, as viewed from the apex, at a relatively constant rate throughout systole, to a maximum value of $\sim 10^{\circ}[3,4]$. The base, initially rotating anticlockwise, reverses direction to give a net clockwise rotation by end-systole (ES) of $\sim 3^{\circ}[3,4]$. The resulting end-systolic torsion (defined to be positive by convention) is often described as being similar to wringing out a wet towel (see Additional file 1 and Additional file 2, and Figure 1). During diastole much of the systolic torsion is released during isovolumic relaxation, due to the mechanical recoil of elastic energy built up during systole [5-7]. Thus, relaxation of torsion is a direct measure of the deactivation of myocytes and release of stored elastic energy, both of which facilitate rapid filling.

Torsion has recently gained increasing attention due to two factors. Firstly, simple and direct methods of

\footnotetext{
* Correspondence: a.young@auckland.ac.nz

Department of Anatomy with Radiology, University of Auckland, Auckland, New Zealand
}

quantification by non-invasive imaging are now widely available. Initially measured using invasively implanted radiopaque or ultrasonic markers $[9,10]$, the current gold standard for evaluation of LV torsion is by CMR tissue tagging [11], but it can also be quantified with echocardiographic speckle tracking [12]. Secondly, torsion is a useful and interesting index of cardiac performance which provides important information on myocardial mechanics that complements standard pump function indices. Torsional deformation is sensitive to changes in endocardial and epicardial contraction, concentric remodeling and the fibrous architecture of the heart. It can therefore provide insight into the mechanical processes of normal and abnormal cardiac function during both contraction and relaxation.

Torsion is remarkably consistent across mammalian species, but is affected (either increased or decreased) by a variety of pathologies, including cardiomyopathies [13], diabetes [8], hypertrophy [14], hypertension [15], and ischemia [16], as well as normal aging [17].

This review firstly provides a discussion of how torsion can provide useful additional information on LV mechanical function, followed by an overview of the current clinical applications of LV torsion. It then provides recommendations for standardized protocols for measuring and reporting torsional motion, and finally suggests some useful avenues for future research. 


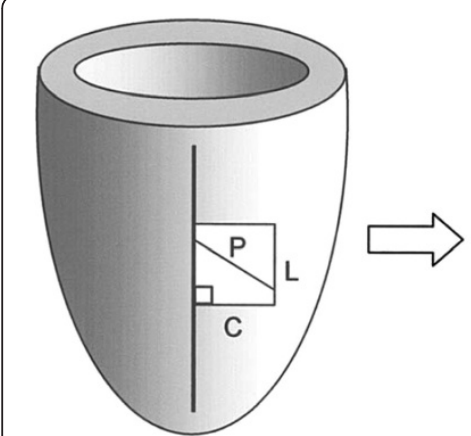

ED

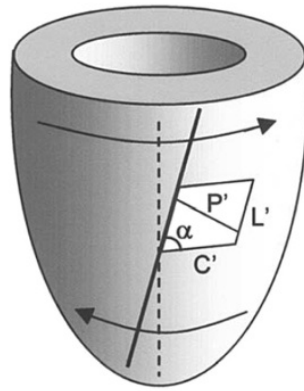

ES
Figure 1 Axial and shear strains during systole. Relative to ED (left), the LV at ES (right) has shortened in both the longitudinal $\left(\mathrm{L} \rightarrow \mathrm{L}^{\prime}\right)$ and circumferential $\left(C \rightarrow C^{\prime}\right)$ directions (axial strains). A characteristic wringing motion (arrows) gives rise to a torsional shear given by the angle $\theta_{C L}=90^{\circ}-\alpha$. One significant effect of torsion is that the greatest shortening $\left(P \rightarrow P^{\prime}\right)$ occurs obliquely to $C$ and $L$, in the approximate direction of the sub-epicardial fibers. From [8] $\odot$ American Journal of Cardiology, used by permission.

\section{Torsion in LV mechanics}

\section{The force balance}

In this paper we define the relative rotation between the apex and base as "twist" and the resulting shear angle $\left(\theta_{\mathrm{CL}}=90^{\circ}-\alpha\right.$ in Figure 1$)$ as "torsion". Torsion therefore describes the shear deformation undergone by the myocardium and is preferred to twist since, for the same torsion, the twist can be variable depending on heart length and diameter. Torsion results from the structural architecture of the mammalian heart, in which subepicardial myofibers are oriented approximately 60 degrees below circumferential in a left handed helix, midwall fibers are oriented circumferentially and subendocardial fibers are oriented approximately 60 degrees above circumferential in a right handed helix (Figure 2). This characteristic architecture gives rise to torsional shear strain as well as axial (circumferential and longitudinal) strain (Figure 1). Mechanical models of ventricular contraction can give insight into the balance of mechanical forces between the different fiber orientations, which leads to the characteristic torsion pattern seen in vivo $[18,19]$. Contraction of the left handed epicardial fibers adds to positive (left handed) systolic torsion while contraction of subendocardial fibers opposes positive torsion. The force balance is typically in favor of the epicardial fibers due to their increased lever arm, given myofiber shortening is relatively uniform across the wall. Torsion therefore gives information about the mechanical function of different fiber populations. The presence of torsion facilitates homogeneous fiber shortening across the wall (Figure 2). In the absence of torsion, endocardial fiber shortening would be greater than seen in vivo (Figure 2), due to the mechanical effects of the contraction of the nearly incompressible myocardium. Torsion also gives

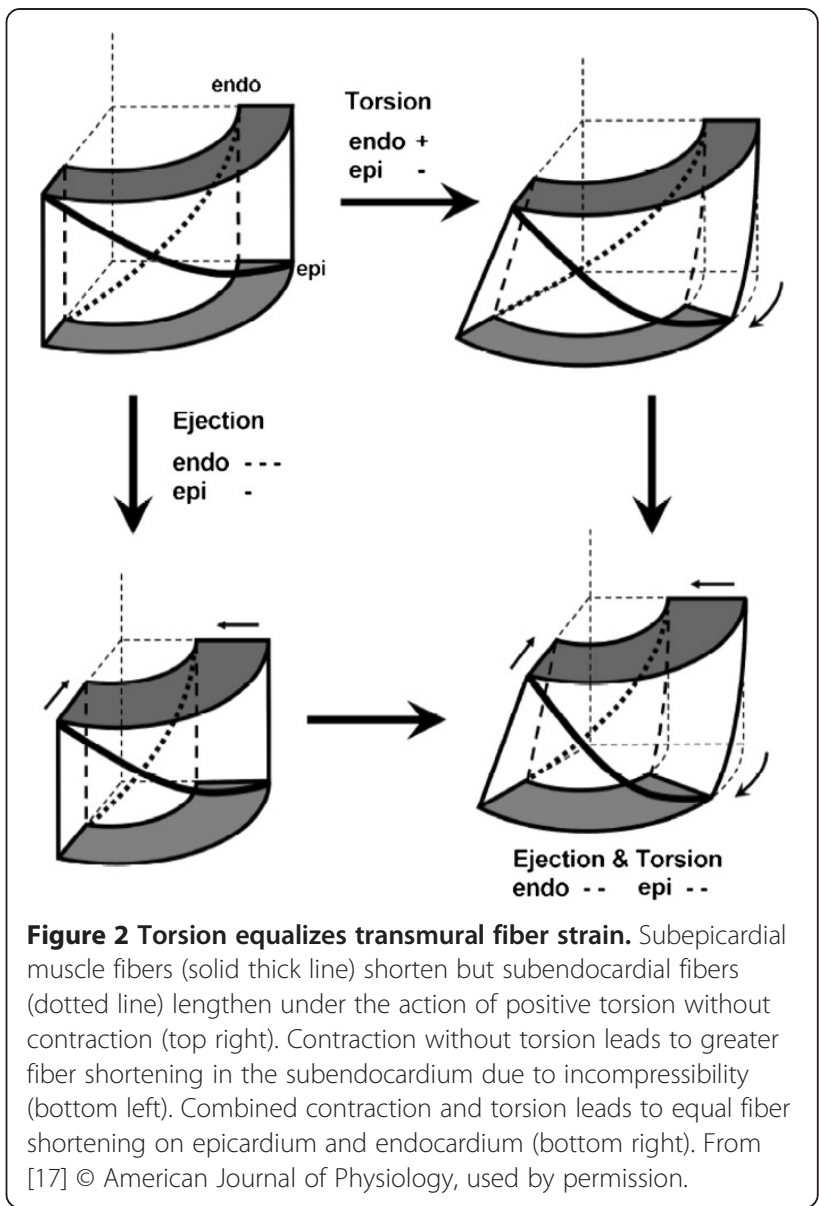

rise to a principal shortening direction (i.e. direction of maximum contraction, $\mathrm{P}$ in Figure 1) which is oriented obliquely to the short axis plane, in the approximate direction of the subepicardial muscle fibers. The direction of the principal shortening is relatively constant across the wall, despite the large change in fiber angle, so that the maximum contraction in the subendocardial wall is approximately orthogonal to the fiber direction [20].

The force balance can be altered by changes in the geometry of the heart. For example LV concentric hypertrophy typically leads to increased torsion due to the thicker heart wall. Epicardial myofibers have a proportionally greater lever arm than endocardial fibers and thus contribute to greater torsion. Conversely eccentric hypertrophy typically leads to decreased torsion.

\section{Torsion and myocardial architecture}

Mathematical models have shown that the normal distribution of myofiber orientation in healthy subjects gives rise to a particular value of torsion which equilibrates fiber contraction and fiber stress across the wall, so that myocytes experience the same force from epicardium to endocardium [18,21]. Torsion is markedly different in conditions where the myofiber architecture is not 
normal. For example, in situs inversus totalis the apical and epicardial basal fiber orientation is normal but the deeper basal fibers have an inverted fiber orientation [22]. Torsion is consequently normal at the apex but changes sign towards the base [23-25]. There is typically no relative rotation between the apex and base, but the midventricular region rotates clockwise relative to both [24] viewed from the apex. Mathematical modeling shows that the predicted torsion arising from a force balance is consistent with that observed in vivo [25].

The remarkable uniformity of fiber strain compared with circumferential or radial strain has led some authors to hypothesize that fiber architecture may adapt in response to strain or force signals to optimize the uniformity of fiber contraction [21]. Simple adaptation laws minimizing cross-fiber shear can act to homogenize fiber strain [26]. The extent to which fiber architecture can adapt under the influence of mechanical signals is an interesting area of future study.

\section{Descriptions of myocardial architecture}

In addition to the myofiber helix angle described above, myofibers can have an imbrication or transverse angle, particularly near the apex and base, in which myofibers travel across the wall from epicardium to endocardium or vice versa [27]. Myocardium is also organized into laminae about 4 cells thick, whose orientations vary in a complex pattern [28]. These laminae are thought to facilitate wall thickening during systole [28]. Due to the complex nature of myocardial architecture, several attempts have been made to rationalize this structure according to geodesics [29], or bands [30]. These can be thought of as conceptual interpretations of the threedimensional branching syncytium [31], but are not recommended for the interpretation of mechanical function. The continuum force balance approach described above has been more useful for this purpose [32].

\section{Torsion to shortening ratio}

Although torsion itself is load dependent [33], the torsion-volume relation is relatively load independent [34]. Mathematical models have shown that a specific relationship between torsion and ejection is required to balance forces and maintain a uniform fiber shortening across the wall $[35,36]$. This leads to a consistent ratio between shortening and torsion during systole across mammalian species, known as the torsion-to-shortening ratio (TSR) [37], which is theoretically independent of contractility, afterload and preload. Changes in this ratio therefore indicate transmural differences in fiber contraction. In particular, models predict that impaired subendocardial function leads to increased TSR, due to a reduced opposition to positive torsion (Figure 2). TSR has been found to be substantially increased in patients with aortic stenosis [37], who are known to have impaired subendocardial function. Smaller increases in TSR can also be seen in normal aging [17], consistent with the hypothesis that endocardial function reduces with age. Russel et al. [38] found increased torsion and TSR in HCM mutation carriers with normal wall thickness, perhaps indicating preclinical subendocardial dysfunction.

\section{Activation and deactivation}

The entire LV is observed to initially rotate counterclockwise. This may be due to the anterior epicardial myofibers extending across the interventricular sulcus to the RV and great vessels [39]. Alternatively, the initial counter-clockwise rotation might be due to the orientation of the great vessels, since it is reversed in situs inversus totalis [24].

During diastole, the recoil rate (rate of relaxation of torsion to end-diastolic values), is faster than the relaxation of axial strains in healthy volunteers [40]. Although torsion typically increases approximately linearly with ejection (relative to end-diastole), much of the endsystolic torsion is typically released during iso-volumic relaxation $[5,6]$. This is likely due to the mechanical release of stored elastic energy in the myocardial tissue [5] and is correlated with the rapid pressure fall and fast inflow during rapid filling [7]. The recoil rate has been shown to be correlated with the time constant of pressure decay, and intraventricular pressure gradients, during relaxation in dogs $[41,42]$ with volume and inotropic interventions. However, some studies in humans with diastolic dysfunction did not show decreased recoil rate, rather the main determinants of recoil rate were peak twist and end systolic volume [43,44].

Another factor influencing the generation of peak torsion and recoil rate may be the phosphorylation of myosin light chain regulatory proteins $[45,46]$. There is a spatial gradient of myosin light chain phosphorylation across the heart wall (from higher values in the epicardium to lower values in the endocardium) [45]. This increases left handed torsion since myosin light chain phosphorylation is associated with increased isometric tension and decreased stretch activation response [45]. In double knockout mice mutants with reduced myosin light chain phosphorylation, reduced torsion and recoil rate were observed consistent with reduced epicardial tension, which were confirmed by multiscale modeling of myosin cycling kinetics in a mechanical model [46].

\section{Torsion and transverse shear}

Although torsion is a shear deformation and therefore volume preserving, it may contribute indirectly to the ejection of blood and the thickening of the ventricular wall during systole. Several studies have noted that 
transverse shears, in which cells slide over one another in the radial (transmural) direction, have a major contribution to the substantial wall thickening observed during systole [47] (Figure 3). Longitudinal-radial transverse shears have been shown to be mechanically facilitated by myocardial laminae, and maximum local shearing is aligned with the laminae orientation in the subendocardium [47-49]. Another type of transverse shear arises due to a difference in systolic rotational motion between epicardium and endocardium (circumferential-radial shear). CMR tagging studies have shown that the apical anticlockwise rotation is greater at the endocardium than the epicardium, and the basal clockwise rotation is greater at the endocardium than the epicardium $[4,10,14]$. This characteristic variation in circumferential-radial shear gives rise to an increase in torsion towards the endocardium $[14,40]$. This is mechanically paradoxical since subendocardial fibers should act to reduce torsion towards the subendocardium, not increase it. One possible mechanism may be the transverse angle of myocardial fibers near the apex and base which can more effectively transmit epicardial forces to the endocardium [50,51]. Although there is some evidence of transverse angle from diffusion tensor MRI [27], whether this is sufficient to predict the observed transverse shear is not yet known. The transmural variation of torsion therefore clearly requires further study.

\section{Clinical applications \\ Aortic stenosis}

Patients with pressure overload hypertrophy due to aortic stenosis typically display increased torsion and prolonged torsional recoil relative to healthy controls or athletes with physiological volume-overload hypertrophy $[15,52]$. This may be indicative of reduced subendocardial function due to regional ischemia, thereby impairing the usual action of subendocardial fibers to oppose torsion [53]. After aortic valve replacement, torsion can be somewhat normalized although still elevated [54].

\section{Ischemia}

In acute ischemia, apical rotation may be initially increased due to relative impairment of subendocardial fibers [55]. In regional ischemia or myocardial infarction, torsion is typically impaired in relation to the regional nature of the disease [11]. In patients with anterolateral myocardial infarction, twist is reduced and untwisting is delayed and prolonged [56-58]. In patients with first time ST elevation myocardial infarction, subendocardial measures of twist appear to be affected before subepicardial twist [16].

\section{Hypertrophy}

Torsion is known to be dependent on LV shape, with reduced twist in more spherical shaped hearts [59] and increased torsion with concentric hypertrophy due to an increased lever arm for epicardial fibers. In hypertrophic cardiomyopathy torsion was found to be increased despite reduced circumferential and longitudinal shortening [14]. Torsion was also increased despite reduced axial strains in patients with type 2 diabetes with diastolic dysfunction but normal ejection fraction [8]. In mild hypertrophy associated with successful repair of coarctation of the aorta [60], torsion was increased despite reduced longitudinal shortening and maintained circumferential shortening. Part of this effect may be due to
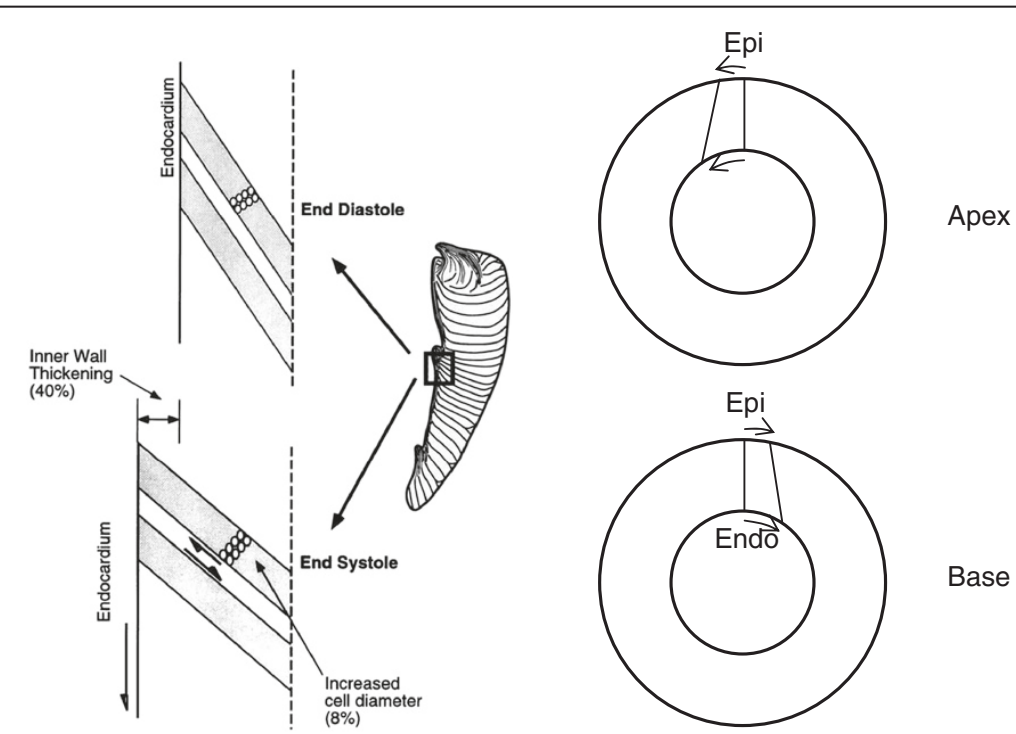

Figure 3 Transverse shears. Left: longitudinal-radial transverse shear is facilitated by myocardial laminae (modified from [47]). Right: circumferential-radial transverse shear is facilitated by increased torsion on the endocardium relative to the epicardium. 
reduced subendocardial shortening. For example, torsion and TSR were also found to be increased in healthy carriers of familial HCM with normal wall thickness [38], perhaps indicating preclinical subendocardial disease.

In volume overload hypertrophy, torsion is typically decreased. Torsion and TSR were reduced after experimentally induced mitral regurgitation in animal studies $[61,62]$. Animals with mitral regurgitation due to infarction showed significantly less torsion and recoil than animals with infarction but no mitral regurgitation [63]. In humans chronic mitral regurgitation leads to reduced torsion and recoil rate [64].

In the physiological hypertrophy seen in elite athletes, torsion can be normal despite increased volume and mass [52]. In a study of athletes imaged before and after running a marathon, both torsion and the magnitude of diastolic recoil were increased, although axial strains were not changed [65]. This finding may be consistent with mild ischemia in the subendocardial layers, but there was no evidence of late gadolinium enhancement [65].

\section{Dyssynchrony}

In a study of cardiac resynchronization therapy (CRT) in patients with LV dyssynchrony due to heart failure, LV twist and torsion were negatively correlated with radial dyssynchrony (difference between earliest and latest segmental peak radial motion), and these were significantly improved after CRT [66]. Twist and torsion were also the best predictors of CRT responders [66]. In contrast, another study found no improvement in twist after CRT [67]. The difference may be due to lead placement, since LV leads positioned in midventricular and apical regions can exhibit a larger increase in systolic LV twist than LV leads positioned in the basal regions of the LV free wall [68]. This finding may be due to the propagation of the activation wavefront, in particular the transmural activation pattern [69]. Sorger et al. have also shown the effects of ectopic activation on torsion development [70].

\section{Diastolic dysfunction}

In pressure overload due to aortic stenosis, relaxation is delayed [15]. The apical untwist is also delayed in older asymptomatic volunteers [71]. In patients with heart failure with preserved ejection fraction, peak twist can be greater than normal in patients with abnormal relaxation (grade 1) decreasing with pseudonormalization pattern (grade 2) and restrictive pattern (grade 3) [72].

\section{Diabetes}

In patients with type 2 diabetes with normal ejection fraction but echocardiographic evidence of diastolic dysfunction, peak systolic torsion was increased relative to controls although peak recoil rate was unchanged [8]. Whether this is due to an increased lever arm due to hypertrophy or a reduced subendocardial fiber shortening is currently unclear. Also, in asymptomatic Type I diabetes patients without morphological evidence of cardiac disease [73], LV torsion was increased despite unaltered circumferential strain, consistent with subendocardial dysfunction due to small vessel disease.

\section{Cardiac iron overload}

In patients with significant iron overload due to repeated transfusions with normal ejection fraction and without heart failure, LV twist was reduced prior to changes in pump function [74]. Torsion and torsional recoil rate were also found to be reduced in patients with transfusion-induced haemochromatosis with myocardial $\mathrm{T} 2 * 10$ msec [75].

\section{Heart failure}

Tachycardia induced heart failure was associated with decreased and delayed systolic torsion and loss of early diastolic recoil [76]. Dilated cardiomyopathy can lead to substantially decreased torsion and earlier peak torsion [13].

\section{Evaluation of interventions}

Hansen et al [9] reported a significant relationship between reductions in torsion and episode of transplant rejection. In a recent study of transplant recipients, a reduction of $25 \%$ or more in torsion predicted Grade 2 or higher rejection with a predictive accuracy of $93 \%$ [77]. Transplant recipients also show less torsion augmentation on exercise than donor-age matched volunteers [78].

In patients with ischemic dilated cardiomyopathy who underwent ventricular reconstruction surgery, those patients with the most reduced torsion before reconstruction showed increased torsion afterwards, but over all patients torsion was not significantly increased [79]. However, torsional recoil rates were increased after ventricular reconstruction surgery over all patients.

\section{Transgenic animal studies}

Torsion may also be a useful biomarker in the study of mechanical effects of genetically manipulated animal models of cardiac disease. In a mouse model of Duchenne muscular dystrophy Li et al. [80] showed initial increased torsion and axial strains in early stages with no fibrosis, and decreased torsion and strain correlating with increased fibrosis in later stages of disease. Torsional changes have also been used to investigate mechanical dysfunction in genetically engineered mouse models of cardiovascular disease $[81,82]$.

\section{Recommendations}

A variety of CMR imaging protocols can be used to evaluate LV torsion, but currently the relative benefits of 
each are not known. Torsion can be quantified using velocity encoded tissue phase mapping [39], spatial modulation of magnetization (SPAMM) [14], complementary spatial modulation of magnetization [52], harmonic phase analysis [81]. Fast methods of analysis have been proposed using the k-space harmonic peaks [83]. Recently, Nasiraei Moghaddam et al. describe a method whereby torsion can be calculated from a single long axis slice using displacement encoded stimulated echo (DENSE) imaging [84]. It may also be possible to quantify torsion from standard SSFP untagged images, using image feature tracking methods [85]. The most complete information however is likely to be provided by 3D displacement encoded CMR imaging, such as 3D DENSE [86].

An example protocol using standard SPAMM imaging would include short axis cine gradient recalled echo segmented k-space SPAMM tagged acquisition with a flip angle of $5-10^{\circ}$ degrees (smaller for better contrast in diastole) grid tagging $45^{\circ}$ to readout direction with $7 \mathrm{~mm}$ spacing, slice thickness $6 \mathrm{~mm}$, repetition time $8 \mathrm{~ms}$, echo time $4 \mathrm{~ms}, 9$ segment view sharing, bandwidth $200 \mathrm{~Hz} /$ pixel, giving 23 frames for a 13 sec breath-hold duration. Slices should include at least two short axis locations, one near the apex but including LV cavity at end-systole, and another near the base but including a full circumference of myocardium at end-systole. Reported reproducibility for twist measurements are typically $0.1^{\circ}$ for interobserver reproducibility [3].

There is currently a lack of standardization for methods used to characterize the twisting motion of the left ventricle. For example, torsion has been calculated as relative rotation (degrees) [11,65], rotation per length (degrees/mm) [52], torsional shear angle (degrees) [36], and shear strain (dimensionless) [14]. A simple difference in rotation between apex and base (often called twist) is not recommended, since this depends on the exact locations of the slices and is difficult to reproduce in longitudinal studies. Twist per unit length of the ventricle is more robust to slice position, since torsion is relatively constant in the longitudinal direction [87], but this measure does not scale appropriately between hearts of different sizes (e.g. mice and humans have comparable ventricular torsion but quite different twist per length). The torsional shear angle shown in Figure 1 is a measure of the change in angle between line segments which are initially aligned with the anatomical circumferential and longitudinal axes of the LV. This measure is independent of size and can be calculated at any point in the ventricle. However, there are several ways in which this can be calculated, as briefly outlined below.

In solid mechanics, the 3D strain state at any point in a body can be fully represented by three axial strains and three shear strains [88]. Referred to the anatomical circumferential, longitudinal and transmural coordinates of the left ventricle, the 3D torsional shear angle is given by

$$
\sin \theta_{C L}=\frac{2 E_{C L}}{\sqrt{1+2 E_{C C}} \sqrt{1+2 E_{L L}}}
$$

where $E_{C C}$ is the circumferential axial strain, $E_{L L}$ is the longitudinal axial strain, and $E_{C L}$ is the circumferentiallongitudinal shear. Russel et al. [87] have noted that the 3D torsional shear angle calculated from the 3D strain tensor (Figure 1) can be influenced by circumferential variation in longitudinal displacement, as well as torsion. Since longitudinal displacement is relatively uniform in the circumferential direction this is typically not a significant effect, and averaging around the circumference will eliminate this variation.

A two-dimensional approximation of the torsional shear angle can be calculated from the relative rotation of two short axis slices, one basal and one apical in location (Figure 4).

Many studies have used the formula given by Aelen et al. [36] which approximates the torsional shear angle by:

$$
\theta_{C L}=\frac{\left(\phi_{\text {apex }}-\phi_{\text {base }}\right)\left(r_{\text {apex }}+r_{\text {base }}\right)}{2 D}
$$

where $\mathrm{D}$ is the distance between slices. Intuitively, this approximates the shear angle from the relative

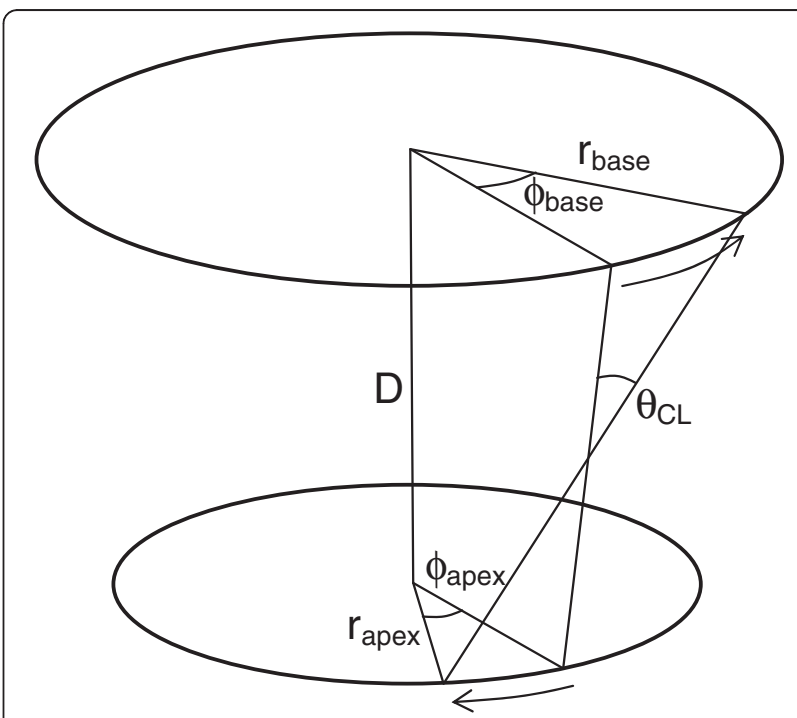

Figure 4 Calculation of torsional shear angle from two short axis slices, one basal and one apical. $r_{\text {apex }} r_{\text {base: }}$ average radius of the cross-section at apical and basal slices respectively. $\varphi_{\text {apex }} \varphi_{\text {base: }}$ average rotation of the cross section at apical and basal slices respectively. D: distance between slices. $\theta_{C L}$ : torsional shear angle. Modified from [89]. 
circumferential displacement of the base and apex (r $\phi)$, assuming $\tan (\theta) \approx \theta$ for small angles. However, this formula assumes that the radii of the apex and base are approximately the same, and can overestimate torsional shear relative to a 3D method [89]. An alternative formula given by Russel et al. [89] calculates the difference in circumferential displacement directly:

$$
\theta_{C L}=\frac{\left(\phi_{\text {apex }} r_{\text {apex }}-\phi_{\text {base }} r_{\text {base }}\right)}{D}
$$

This version has been found to give unbiased estimates of the 3D torsional shear angle even in cases with high torsion [89].

Since it has been used in many previous studies, is easy to understand, and relatively invariant to ventricular size and slice position, equation 2 is recommended for the simple calculation of torsion from two short axis slices. However, for direct comparison with the 3D torsional shear, equation 3 is more appropriate. Regional torsion, for example referred to the standard 17 segment model, should not be calculated using either equations 2 or 3 , since regional estimates are highly sensitive to the exact position of the axis of rotation [87]. For regional estimates, the $3 \mathrm{D}$ torsional shear (equation 1) is recommended.

For diastolic function, increased torsion generally leads to increased torsional recoil [90,91]. For example, peak torsion was increased in patients with type 2 diabetes, diastolic dysfunction and normal ejection fraction, whereas torsional recoil rate was normal [8], leading to impaired recoil relative to the peak torsion. Therefore torsional recoil rate should be normalized by peak systolic torsion.

\section{Future work}

Investigation of the relationship between torsional deformation and the microstructure of the heart, together with the changes due to disease, is likely to be a fruitful area of future research. Detailed information on the myofiber architecture can be obtained from diffusion tensor and diffusion spectrum imaging [92,93]. Although to date most studies have required isolated arrested hearts, in-vivo measurement of myofiber architecture is an active area of current research [94].

One interesting open question is whether patients with heart failure and normal ejection fraction have impaired relaxation of torsion, since some studies have not found any significant difference [44]. One hypothesis is that, like diabetic patients with normal ejection fraction and grade 1 diastolic dysfunction [8], peak twist may be increased and recoil rate unchanged, leading to reduced recoil rate relative to peak twist [91]. As the disease progresses, systolic dysfunction may lead to impaired recoil.
The relationship between recoil rate and pressure drop in the LV also needs further investigation, correcting for the effects of peak torsion and end-systolic volume [43].

Population-based statistical models of cardiac function are now becoming available [95], in which regional wall motion can be mapped to a standard atlas of the heart and statistical tests performed to quantify the degree of abnormality. These atlases will be useful in characterizing the expected range of torsion in patient subgroups.

A combination of population imaging and mechanical modelling is required to understand the mechanism for the increased torsion found in the subendocardium, and the coupling mechanism which generates transverse shear and wall thickening. In particular, further work is needed on the torsion to shortening ratio to determine if the predictions of computational physiological models of cardiac mechanics [96] are experimentally verified. Higher resolution non-invasive strain imaging methods such as 3D transmural displacement imaging with DENSE MRI [86] show a lot of promise in this regard.

\section{Conclusions}

Torsion is an important index of cardiac function and provides additional information on myocardial performance over and above standard pump function indices. Although it is readily performed as part of any CMR examination, standardized methods of calculation are recommended. Torsion provides information on the relative mechanical influence of subendocardial vs subepicardial fibers, and will be particularly useful in characterizing mechanisms through the customization of mathematical models to individual patient torsion.

\section{Additional files}

Additional file 1: JCMR Torsion Movie Base.avi.

Additional file 2: JCMR Torsion Movie Apex.avi.

Competing interests

AAY and BRC act as consultants for Siemens Medical Solutions.

\section{Authors' contributions}

AAY performed the literature review. Both authors (AAY and BRC)

contributed in the design and writing of the manuscript, and approved the final manuscript.

\section{Acknowledgements}

This work was supported by the Health Research Council of New Zealand (06/463) and the National Institutes of Health USA (R01HL087773).

Received: 1 February 2012 Accepted: 24 July 2012

Published: 24 July 2012

\section{References}

1. Streeter DD Jr, Spotnitz HM, Patel DP, Ross J Jr, Sonnenblick EH: Fiber orientation in the canine left ventricle during diastole and systole. Circ Res 1969, 24:339-347.

2. Greenbaum RA, Ho SY, Gibson DG, Becker AE, Anderson RH: Left ventricular fibre architecture in man. Br Heart J 1981, 45:248-263. 
3. Lorenz $\mathrm{CH}$, Pastorek JS, Bundy JM: Delineation of normal human left ventricular twist throughout systole by tagged cine magnetic resonance imaging. J Cardiovasc Magn Reson 2000, 2:97-108.

4. Young AA, Imai $H$, Chang CN, Axel L: Two-dimensional left ventricular deformation during systole using magnetic resonance imaging with spatial modulation of magnetization. Circulation 1994 89:740-752.

5. Rademakers FE, Buchalter MB, Rogers WJ, Zerhouni EA, Weisfeldt ML, Weiss $J$, Shapiro EP: Dissociation between left ventricular untwisting and filling. Accentuation by catecholamines. Circulation 1992, 85:1572-1581.

6. Ashikaga $\mathrm{H}$, Criscione JC, Omens JH, Covell JW, Ingels NB Jr: Transmural left ventricular mechanics underlying torsional recoil during relaxation. Am J Physiol Heart Circ Physiol 2004, 286:H640-647.

7. Notomi Y, Martin-Miklovic MG, Oryszak SJ, Shiota T, Deserranno D, Popovic ZB, Garcia MJ, Greenberg NL, Thomas JD: Enhanced ventricular untwisting during exercise: a mechanistic manifestation of elastic recoil described by Doppler tissue imaging. Circulation 2006, 113:2524-2533.

8. Fonseca CG, Dissanayake AM, Doughty RN, Whalley GA, Gamble GD, Cowan BR, Occleshaw CJ, Young AA: Three-dimensional assessment of left ventricular systolic strain in patients with type 2 diabetes mellitus, diastolic dysfunction, and normal ejection fraction. Am J Cardio/ 2004, 94:1391-1395

9. Hansen DE, Daughters GT 2nd, Alderman EL, Stinson EB, Baldwin JC, Miller DC: Effect of acute human cardiac allograft rejection on left ventricular systolic torsion and diastolic recoil measured by intramyocardial markers. Circulation 1987, 76:998-1008.

10. Ingels NB Jr, Hansen DE, Daughters GT 2nd, Stinson EB, Alderman EL, Miller DC: Relation between longitudinal, circumferential, and oblique shortening and torsional deformation in the left ventricle of the transplanted human heart. Circ Res 1989, 64:915-927.

11. Buchalter MB, Rademakers FE, Weiss JL, Rogers WJ, Weisfeldt ML, Shapiro EP. Rotational deformation of the canine left ventricle measured by magnetic resonance tagging: effects of catecholamines, ischaemia, and pacing. Cardiovasc Res 1994, 28:629-635.

12. Helle-Valle T, Crosby J, Edvardsen T, Lyseggen E, Amundsen BH, Smith HJ, Rosen BD, Lima JA, Torp H, Ihlen H, Smiseth OA: New noninvasive method for assessment of left ventricular rotation: speckle tracking echocardiography. Circulation 2005, 112:3149-3156.

13. Kanzaki H, Nakatani S, Yamada N, Urayama S, Miyatake K, Kitakaze M: Impaired systolic torsion in dilated cardiomyopathy: reversal of apical rotation at mid-systole characterized with magnetic resonance tagging method. Basic Res Cardiol 2006, 101:465-470.

14. Young AA, Kramer CM, Ferrari VA, Axel L, Reichek N: Three-dimensional left ventricular deformation in hypertrophic cardiomyopathy. Circulation 1994, 90:854-867.

15. Nagel E, Stuber M, Burkhard B, Fischer SE, Scheidegger MB, Boesiger P, Hess $\mathrm{OM}$ : Cardiac rotation and relaxation in patients with aortic valve stenosis. Eur Heart J 2000, 21:582-589.

16. Bertini M, Delgado V, Nucifora G, Ajmone Marsan N, Ng AC, Shanks M, Antoni ML, van de Veire NR, van Bommel RJ, Rapezzi C, et al.: Left ventricular rotational mechanics in patients with coronary artery disease: differences in subendocardial and subepicardial layers. Heart 2010, 96:1737-1743.

17. Lumens J, Delhaas T, Arts T, Cowan BR, Young AA: Impaired subendocardial contractile myofiber function in asymptomatic aged humans, as detected using MRI. Am J Physiol Heart Circ Physiol 2006, 291:H1573-1579.

18. Arts T, Reneman RS, Veenstra PC: A model of the mechanics of the left ventricle. Ann Biomed Eng 1979, 7:299-318.

19. Taber LA, Yang M, Podszus WW: Mechanics of ventricular torsion. J Biomech 1996, 29:745-752.

20. Waldman LK, Nosan D, Villarreal F, Covell JW: Relation between transmural deformation and local myofiber direction in canine left ventricle. Circ Res 1988, 63:550-562.

21. Rijcken J, Bovendeerd PH, Schoofs AJ, van Campen DH, Arts T: Optimization of cardiac fiber orientation for homogeneous fiber strain during ejection. Ann Biomed Eng 1999, 27:289-297.

22. Delhaas T, Decaluwe W, Rubbens M, Kerckhoffs R, Arts T: Cardiac fiber orientation and the left-right asymmetry determining mechanism. Ann N Y Acad Sci 2004, 1015:190-201.
23. Delhaas T, Kroon W, Bovendeerd P, Arts T: Left ventricular apical torsion and architecture are not inverted in situs inversus totalis. Prog Biophys Mol Biol 2008, 97:513-519.

24. Delhaas T, Kroon W, Decaluwe W, Rubbens M, Bovendeerd P, Arts T: Structure and torsion of the normal and situs inversus totalis cardiac left ventricle. I. Experimental data in humans. Am J Physiol Heart Circ Physiol 2008, 295:H197-201.

25. Kroon W, Delhaas T, Bovendeerd P, Arts T: Structure and torsion in the normal and situs inversus totalis cardiac left ventricle. II. Modeling cardiac adaptation to mechanical load. Am J Physiol Heart Circ Physiol 2008, 295:H202-210.

26. Kroon W, Delhaas T, Bovendeerd P, Arts T: Computational analysis of the myocardial structure: adaptation of cardiac myofiber orientations through deformation. Med Image Anal 2009, 13:346-353.

27. Geerts $L$, Bovendeerd P, Nicolay K, Arts T: Characterization of the normal cardiac myofiber field in goat measured with MR-diffusion tensor imaging. Am J Physiol Heart Circ Physiol 2002, 283:H139-145.

28. LeGrice IJ, Smaill BH, Chai LZ, Edgar SG, Gavin JB, Hunter PJ: Laminar structure of the heart: ventricular myocyte arrangement and connective tissue architecture in the dog. Am J Physiol 1995, 269:H571-582.

29. Jouk PS, Usson Y, Michalowicz G, Grossi L: Three-dimensional cartography of the pattern of the myofibres in the second trimester fetal human heart. Anat Embryol (Berl) 2000, 202:103-118

30. Torrent-Guasp F, Kocica MJ, Corno AF, Komeda M, Carreras-Costa F, Flotats A, Cosin-Aguillar J, Wen H: Towards new understanding of the heart structure and function. Eur J Cardiothorac Surg 2005, 27:191-201.

31. Gilbert SH, Benson AP, Li P, Holden AV: Regional localisation of left ventricular sheet structure: integration with current models of cardiac fibre, sheet and band structure. Eur J Cardiothorac Surg 2007, 32:231-249.

32. Criscione JC, Rodriguez F, Miller DC: The myocardial band: simplicity can be a weakness. Eur J Cardiothorac Surg 2005, 28:363-364. author reply 364-367.

33. MacGowan GA, Burkhoff D, Rogers WJ, Salvador D, Azhari H, Hees PS, Zweier JL, Halperin HR, Siu CO, Lima JA, et al.: Effects of afterload on regional left ventricular torsion. Cardiovasc Res 1996, 31:917-925.

34. Dong SJ, Hees PS, Huang WM, Buffer SA Jr, Weiss JL, Shapiro EP. Independent effects of preload, afterload, and contractility on left ventricular torsion. Am J Physiol 1999, 277:H1053-1060.

35. Arts T, Meerbaum S, Reneman RS, Corday E: Torsion of the left ventricle during the ejection phase in the intact dog. Cardiovasc Res 1984, 18:183-193.

36. Aelen FW, Arts T, Sanders DG, Thelissen GR, Muijtjens AM, Prinzen FW, Reneman RS: Relation between torsion and cross-sectional area change in the human left ventricle. J Biomech 1997, 30:207-212.

37. Delhaas T, Kotte J, van der Toorn A, Snoep G, Prinzen FW, Arts T: Increase in left ventricular torsion-to-shortening ratio in children with valvular aortic stenosis. Magn Reson Med 2004, 51:135-139.

38. Russel IK, Brouwer WP, Germans T, Knaapen P, Marcus JT, van der Velden J, Gotte MJ, van Rossum AC: Increased left ventricular torsion in hypertrophic cardiomyopathy mutation carriers with normal wall thickness. J Cardiovasc Magn Reson 2011, 13:3.

39. Codreanu I, Robson MD, Golding SJ, Jung BA, Clarke K, Holloway CJ: Longitudinally and circumferentially directed movements of the left ventricle studied by cardiovascular magnetic resonance phase contrast velocity mapping. J Cardiovasc Magn Reson 2011, 12:48.

40. Kuijer JP, Marcus JT, Gotte MJ, van Rossum AC, Heethaar RM: Threedimensional myocardial strains at end-systole and during diastole in the left ventricle of normal humans. J Cardiovasc Magn Reson 2002, 4:341-351.

41. Dong SJ, Hees PS, Siu CO, Weiss JL, Shapiro EP: MRI assessment of LV relaxation by untwisting rate: a new isovolumic phase measure of tau. Am J Physiol Heart Circ Physiol 2001, 281:H2002-2009.

42. Notomi Y, Popovic ZB, Yamada H, Wallick DW, Martin MG, Oryszak SJ, Shiota T, Greenberg NL, Thomas JD: Ventricular untwisting: a temporal link between left ventricular relaxation and suction. Am J Physiol Heart Circ Physiol 2008, 294:H505-513.

43. Wang J, Khoury DS, Yue Y, Torre-Amione G, Nagueh SF: Left ventricular untwisting rate by speckle tracking echocardiography. Circulation 2007, 116:2580-2586.

44. Wang J, Khoury DS, Yue Y, Torre-Amione G, Nagueh SF: Preserved left ventricular twist and circumferential deformation, but depressed 
longitudinal and radial deformation in patients with diastolic heart failure. Eur Heart J 2008, 29:1283-1289.

45. Davis JS, Hassanzadeh S, Winitsky S, Lin H, Satorius C, Vemuri R, Aletras AH, Wen $H$, Epstein ND: The overall pattern of cardiac contraction depends on a spatial gradient of myosin regulatory light chain phosphorylation. Cell 2001, 107:631-641.

46. Sheikh F, Ouyang K, Campbell SG, Lyon RC, Chuang J, Fitzsimons D, Tangney J, Hidalgo CG, Chung CS, Cheng H, et al.: Mouse and computational models link Mlc2v dephosphorylation to altered myosin kinetics in early cardiac disease. J Clin Invest 2012, 122:1209-1221.

47. LeGrice IJ, Takayama Y, Covell JW: Transverse shear along myocardial cleavage planes provides a mechanism for normal systolic wall thickening. Circ Res 1995, 77:182-193.

48. Costa KD, Takayama Y, McCulloch AD, Covell JW: Laminar fiber architecture and three-dimensional systolic mechanics in canine ventricular myocardium. Am J Physiol 1999, 276:H595-607.

49. Cheng A, Nguyen TC, Malinowski M, Daughters GT, Miller DC, Ingels NB Jr: Heterogeneity of left ventricular wall thickening mechanisms. Circulation 2008, 118:713-721.

50. Ubbink SW, Bovendeerd PH, Delhaas T, Arts T, van de Vosse FN: Towards model-based analysis of cardiac MR tagging data: relation between left ventricular shear strain and myofiber orientation. Med Image Anal 2006, 10:632-641.

51. Bovendeerd PH, Kroon W, Delhaas T: Determinants of left ventricular shear strain. Am J Physiol Heart Circ Physiol 2009, 297:H1058-1068.

52. Stuber M, Scheidegger MB, Fischer SE, Nagel E, Steinemann F, Hess OM, Boesiger $P$ : Alterations in the local myocardial motion pattern in patients suffering from pressure overload due to aortic stenosis. Circulation 1999, 100:361-368.

53. Van Der Toorn A, Barenbrug P, Snoep G, Van Der Veen FH, Delhaas T, Prinzen FW, Maessen J, Arts T: Transmural gradients of cardiac myofiber shortening in aortic valve stenosis patients using MRI tagging. Am J Physiol Heart Circ Physiol 2002, 283:H1609-1615.

54. Sandstede JJ, Johnson T, Harre K, Beer M, Hofmann S, Pabst T, Kenn W Voelker W, Neubauer S, Hahn D: Cardiac systolic rotation and contraction before and after valve replacement for aortic stenosis: a myocardial tagging study using MR imaging. AJR Am J Roentgenol 2002, 178:953-958.

55. Kroeker CA, Tyberg JV, Beyar R: Effects of ischemia on left ventricular apex rotation. An experimental study in anesthetized dogs. Circulation 1995, 92:3539-3548.

56. Nagel E, Stuber M, Lakatos M, Scheidegger MB, Boesiger P, Hess OM: Cardiac rotation and relaxation after anterolateral myocardial infarction. Coron Artery Dis 2000, 11:261-267.

57. Takeuchi M, Nishikage T, Nakai H, Kokumai M, Otani S, Lang RM: The assessment of left ventricular twist in anterior wall myocardial infarction using two-dimensional speckle tracking imaging. J Am Soc Echocardiogr 2007, 20:36-44.

58. Garot J, Pascal O, Diebold B, Derumeaux G, Gerber BL, Dubois-Rande JL, Lima JA, Gueret P: Alterations of systolic left ventricular twist after acute myocardial infarction. Am J Physiol Heart Circ Physiol 2002, 282:H357-362.

59. van Dalen BM, Kauer F, Vletter WB, Soliman OI, van der Zwaan HB, Ten Cate FJ, Geleijnse ML: Influence of cardiac shape on left ventricular twist. J Appl Physiol 2010, 108:146-151.

60. Young AA, Cowan BR, Occleshaw CJ, Oxenham HC, Gentles TL: Temporal evolution of left ventricular strain late after repair of coarctation of the aorta using 3D MR tissue tagging. J Cardiovasc Magn Reson 2002, 4:233-243.

61. Ennis DB, Nguyen TC, Itoh A, Bothe W, Liang DH, Ingels NB, Miller DC: Reduced systolic torsion in chronic "pure" mitral regurgitation. Circ Cardiovasc Imaging 2009, 2:85-92.

62. Tibayan FA, Yun KL, Fann Jl, Lai DT, Timek TA, Daughters GT, Ingels NB, Miller DC: Torsion dynamics in the evolution from acute to chronic mitral regurgitation. J Heart Valve Dis 2002, 11:39-46. discussion 46.

63. Tibayan FA, Rodriguez F, Langer F, Zasio MK, Bailey L, Liang D, Daughters GT, Ingels NB Jr, Miller DC: Alterations in left ventricular torsion and diastolic recoil after myocardial infarction with and without chronic ischemic mitral regurgitation. Circulation 2004, 110:|1109-114.

64. Borg AN, Harrison JL, Argyle RA, Ray SG: Left ventricular torsion in primary chronic mitral regurgitation. Heart 2008, 94:597-603.

65. Hanssen H, Keithahn A, Hertel G, Drexel V, Stern H, Schuster T, Lorang D, Beer AJ, Schmidt-Trucksass A, Nickel T, et al.: Magnetic resonance imaging of myocardial injury and ventricular torsion after marathon running. Clin Sci (Lond) 2011, 120:143-152.

66. Sade LE, Demir O, Atar I, Muderrisoglu H, Ozin B: Effect of mechanical dyssynchrony and cardiac resynchronization therapy on left ventricular rotational mechanics. Am J Cardiol 2008, 101:1163-1169.

67. Zhang Q, Fung JW, Yip GW, Chan JY, Lee AP, Lam YY, Wu LW, Wu EB, Yu CM: Improvement of left ventricular myocardial short-axis, but not longaxis function or torsion after cardiac resynchronisation therapy: an assessment by two-dimensional speckle tracking. Heart 2008 , 94:1464-1471.

68. Bertini M, Marsan NA, Delgado V, van Bommel RJ, Nucifora G, Borleffs CJ, Boriani G, Biffi M, Holman ER, van der Wall EE, et al.: Effects of cardiac resynchronization therapy on left ventricular twist. J Am Coll Cardio/ 2009, 54:1317-1325

69. Bertini M, Sengupta PP, Nucifora G, Delgado V, Ng AC, Marsan NA, Shanks M, van Bommel RJ, Schalij MJ, Narula J, Bax JJ: Role of left ventricular twist mechanics in the assessment of cardiac dyssynchrony in heart failure. JACC CardiovasC Imaging 2009, 2:1425-1435.

70. Sorger JM, Wyman BT, Faris OP, Hunter WC, McVeigh ER: Torsion of the left ventricle during pacing with MRI tagging. J Cardiovasc Magn Reson 2003, 5:521-530.

71. Oxenham HC, Young AA, Cowan BR, Gentles TL, Occleshaw CJ, Fonseca CG, Doughty RN, Sharpe N: Age-related changes in myocardial relaxation using three-dimensional tagged magnetic resonance imaging. J Cardiovasc Magn Reson 2003, 5:421-430.

72. Park SJ, Miyazaki C, Bruce CJ, Ommen S, Miller FA, Oh JK: Left ventricular torsion by two-dimensional speckle tracking echocardiography in patients with diastolic dysfunction and normal ejection fraction. J Am Soc Echocardiogr 2008, 21:1129-1137.

73. Chung J, Abraszewski P, Yu X, Liu W, Krainik AJ, Ashford M, Caruthers SD, McGill JB, Wickline SA: Paradoxical increase in ventricular torsion and systolic torsion rate in type I diabetic patients under tight glycemic control. J Am Coll Cardiol 2006, 47:384-390.

74. Seldrum S, Pierard S, Moniotte S, Vermeylen C, Vancraeynest D, Pasquet A, Vanoverschelde $\mathrm{J}$, Gerber BL: Iron overload in polytransfused patients without heart failure is associated with subclinical alterations of systolic left ventricular function using cardiovascular magnetic resonance tagging. J Cardiovasc Magn Reson 2011, 13:23.

75. Leung MC CBG, Carbone A, Young AA, Cowan BR, Pontre B, Teo K, St Pierre T, Worthley SG: Myocardial T2* affects 3D MRI myocardial strain in patients with transfusion-induced haemochromatosis. Circulation 2007 116:|I_459-II_460.

76. Tibayan FA, Lai DT, Timek TA, Dagum P, Liang D, Daughters GT, Ingels NB, Miller DC: Alterations in left ventricular torsion in tachycardia-induced dilated cardiomyopathy. J Thorac Cardiovasc Surg 2002, 124:43-49.

77. Sato T, Kato TS, Kamamura K, Hashimoto S, Shishido T, Mano A, Oda N, Takahashi A, Ishibashi-Ueda H, Nakatani T, et al.: Utility of left ventricular systolic torsion derived from 2-dimensional speckle-tracking echocardiography in monitoring acute cellular rejection in heart transplant recipients. J Heart Lung Transplant 2010, 30 5:536-543.

78. Esch BT, Scott JM, Warburton DE, Thompson R, Taylor D, Cheng Baron J, Paterson I, Haykowsky MJ: Left ventricular torsion and untwisting during exercise in heart transplant recipients. J Physio/ 2009, 587:2375-2386.

79. Setser RM, Smedira NG, Lieber ML, Sabo ED, White RD: Left ventricular torsional mechanics after left ventricular reconstruction surgery for ischemic cardiomyopathy. J Thorac Cardiovasc Surg 2007, 134:888-896.

80. Li W, Liu W, Zhong J, Yu X: Early manifestation of alteration in cardiac function in dystrophin deficient mdx mouse using 3D CMR tagging. J Cardiovasc Magn Reson 2009, 11:40.

81. Chuang JS, Zemljic-Harpf A, Ross RS, Frank LR, McCulloch AD, Omens JH: Determination of three-dimensional ventricular strain distributions in gene-targeted mice using tagged MRI. Magn Reson Med 2010, 64:1281-1288.

82. Weis SM, Emery JL, Becker KD, McBride DJ Jr, Omens JH, McCulloch AD: Myocardial mechanics and collagen structure in the osteogenesis imperfecta murine (oim). Circ Res 2000, 87:663-669.

83. Reyhan M, Natsuaki Y, Ennis DB: Fourier analysis of STimulated echoes (FAST) for the quantitative analysis of left ventricular twist. J Magn Reson Imaging 2011.

84. Nasiraei Moghaddam A, Saber NR, Wen H, Finn JP, Ennis DB, Gharib M: Analytical method to measure three-dimensional strain patterns in the 
left ventricle from single slice displacement data. J Cardiovasc Magn Reson 2010, 12:33.

85. Schuster A, Kutty S, Padiyath A, Parish V, Gribben P, Danford DA, Makowski MR, Bigalke B, Beerbaum P, Nagel E: Cardiovascular magnetic resonance myocardial feature tracking detects quantitative wall motion during dobutamine stress. J Cardiovasc Magn Reson 2011, 13:58.

86. Zhong X, Spottiswoode BS, Meyer CH, Kramer CM, Epstein FH: Imaging three-dimensional myocardial mechanics using navigator-gated volumetric spiral cine DENSE MRI. Magn Reson Med 2010, 64:1089-1097.

87. Russel IK, Gotte MJ, Kuijer JP, Marcus JT: Regional assessment of left ventricular torsion by CMR tagging. J Cardiovasc Magn Reson 2008, 10:26

88. Fung YC: Foundations of solid mechanics. Englewood Cliffs: Prentice Hall; 1965.

89. Russel IK, Tecelao SR, Kuijer JP, Heethaar RM, Marcus JT: Comparison of 2D and 3D calculation of left ventricular torsion as circumferentiallongitudinal shear angle using cardiovascular magnetic resonance tagging. J Cardiovasc Magn Reson 2009, 11:8.

90. Fonseca CG, Oxenham HC, Cowan BR, Occleshaw CJ, Young AA: Aging alters patterns of regional nonuniformity in LV strain relaxation: a 3-D MR tissue tagging study. Am J Physiol Heart Circ Physiol 2003, 285:H621-630

91. Thompson RB, Paterson I, Chow K, Cheng-Baron J, Scott JM, Esch BT, Ennis DB, Haykowsky MJ: Characterization of the relationship between systolic shear strain and early diastolic shear strain rates: insights into torsional recoil. Am J Physiol Heart Circ Physiol 2010, 299:H898-907.

92. Rohmer D, Sitek A, Gullberg GT: Reconstruction and visualization of fiber and laminar structure in the normal human heart from ex vivo diffusion tensor magnetic resonance imaging (DTMRI) data. Invest Radiol 2007, 42:777-789.

93. Sosnovik DE, Wang R, Dai G, Reese TG, Wedeen VJ: Diffusion MR tractography of the heart. J Cardiovasc Magn Reson 2009, 11:47.

94. Gamper U, Boesiger P, Kozerke S: Diffusion imaging of the in vivo heart using spin echoes-considerations on bulk motion sensitivity. Magn Reson Med 2007, 57:331-337.

95. Fonseca CG, Backhaus M, Bluemke DA, Britten RD, Chung JD, Cowan BR, Dinov ID, Finn JP, Hunter PJ, Kadish AH, et al.: The Cardiac Atlas Project-an imaging database for computational modeling and statistical atlases of the heart. Bioinformatics 2011, 27:2288-2295.

96. Wang VY, Lam HI, Ennis DB, Cowan BR, Young AA, Nash MP: Modelling passive diastolic mechanics with quantitative MRI of cardiac structure and function. Med Image Anal 2009, 13:773-784.

doi:10.1186/1532-429X-14-49

Cite this article as: Young and Cowan: Evaluation of left ventricular torsion by cardiovascular magnetic resonance. Journal of Cardiovascular Magnetic Resonance 2012 14:49.

\section{Submit your next manuscript to BioMed Central and take full advantage of:}

- Convenient online submission

- Thorough peer review

- No space constraints or color figure charges

- Immediate publication on acceptance

- Inclusion in PubMed, CAS, Scopus and Google Scholar

- Research which is freely available for redistribution 